\title{
Analysis on Henan Science and Technology Talent Environment Evaluation in the Factor Analysis Perspective
}

\author{
Ge Bai ${ }^{1, a}$ \\ ${ }^{1}$ Party School of Ji Yuan Municipal Committee of the CPC, Jiyuan, Henan, China, 459000
}

Keywords: Henan Province, Talent Environment, Evaluation, Factor Analysis

\begin{abstract}
Talent environment directly affect the training and development of personnel. It is a large complex system, so for the evaluation of talent but also the environment in simple terms, the layers of analysis. Follow a collection of, comparability, non-recurring and other principle, choose economic development, five aspects of entrepreneurial talent and develop security status 18 indicators Evaluation Index System talent environment, factor analysis of Henan Province 13 prefecture-level City to evaluate talent environment
\end{abstract}

\section{Introduction}

Increased focus on talent environment, the establishment of scientific and rational personnel evaluation system environment, not only help to identify talent in the environment the problems, but also for management personnel, to attract and retain qualified personnel, and tap the potential talent is important. Compared with other environmental evaluations, talent environment directly reflects the quality of human survival and development, emphasizing the systematic analysis of human resources. In comparison with the traditional talent environmental assessment, environmental assessment of modern people pay more attention to people's ability, motivation and personal style, not just how much talent the knowledge mastered. Thus, for the evaluation of regional talent environment should consider the following aspects: (1) whether there is talent environment conducive to the cultivation of talents in the region; (2) whether it is conducive to play in the region's potential talent; (3) whether there conducive to attracting top talent in the region to contribute; (4) whether there is conducive to the sustainable development of the region's talent environment. Based on four basic principles above, we will design a personnel evaluation system environment and through the 13 prefecture-level city in Henan empirical analysis reveals in Jiangsu Province Talent environment.

\section{The Structure of the Human Environment}

In the process of human growth and development, the environment always takes place continuously in action, sometimes plays a decisive role. Suitable environment can encourage and promote the growth and development of talent, harsh environments may restrict, impede growth and development of talent. From the perspective of the social system, the political, economic, cultural status, education level of development, talent management system, social customs, personnel unit where individuals, geographical situation, interpersonal environment, as well as family, love, marital status and many other factors that make up a society environment network, from all levels of their influence on the growth and development of talent. Given the complexity of the human environment, we can learn from multiple perspectives talent structure further environmental awareness:

It consists of personnel from the environment and it is a natural geographic environment, social environment and the personnel policy of the environment. Deterministic role in human survival and development of the geographical environment and it is the base layer of talent environment. The effect on people and society and human social environment of the domestic and international environment there is uncertainty, the middle layer of talent environment. Personnel policy environment is the direct effect on the human environment of the uppermost layer, which directly affects the training, development and utilization. 
It is people-centered, from human needs, development, entrepreneurship and self-realization perspective, talent environment can be divided into three levels, namely on the basis of talent environment, personnel environment and leading talent-driven environment. Talent base environment includes the development of entrepreneurial talent political environment, economic environment, human environment, to protect the ecological environment and living environment. Talent is talent development environment leading entrepreneurial stage, needs and requirements of the social environment in which people presented a two-way relationship choice. Talent is the driving environment condition and motivates talented people to conditions, including personnel selection methods, talent incentive mechanism.

It from the point of view constitute, talent environment, including macro-environment, the concept of environment and micro environment. Talent macroeconomic environment is a strategic environment, which features strategic talent development or strategic impact. In general, human macro environmental factors include political environment, economic environment, social environment and technological environment. Due to the overall development strategy for these elements change will have an impact on people, it is necessary to take action involving the entire talent development strategy to adapt to changes in these environmental factors. Talent is talent in the concept of environmental industry environment, which means that elements have a competitive force in the industry meaning or significance of balanced structure. Based on changes in the competitive industry five forces model Porter, an industry economic structure, the intensity of competition and, ultimately, the potential profit is determined by the competitor the threat of substitute products, customers and suppliers force strength

The five forces intertwined effect, constitute the concept of talent in the environment. Talent is talent micro-environment unit environment, which means that elements of the unit factors in business activities that create value. Value chain analysis along the lines of \# Michael Porter in "competitive advantage" is mentioned, people can be divided into micro-environment of the enterprise basic activities and support activities. The basic activities of enterprises are by the internal logistics, production, external logistics, marketing, and services consisting of five kinds of activities, which are the main activities of the enterprise, namely, the production and business activities. Business support activities include two aspects: First, to support the entire value chain to ensure that the basic structure consisting of general management, finance, planning, real estate management, and quality; the second is to support both the entire value chain and support three basic activities kinds of activities, namely procurement, technology development and human resources management.

In summary, the talent environment is a huge complex system. Thus, for the evaluation of talent environment it is but also easy to understand, down to every level. In order to make research more relevant, we evaluated the talent environment is highly relevant mainly to those with talent development, a greater degree of influence or having a key role in the macro-environmental factors, including economic factors, social factors and technological factors and three aspects.

\section{The Design of Talent Environment Evaluation System}

The Basic Principles of Talent Environmental Assessment System Design. (1) It can be collected principle. Because the Talent Evaluation System for Environmental talents in today's society, use, optimization so important. Therefore the choice of evaluation should have sex can be collected. This research will be able to obtain a wide range of application and promotion in real life, to provide scientific guidance for the creation of reasonable talent environment and optimal allocation of human resources. (2) The comparative principle. Talent Environment is a comprehensive reflection of economic, social and political impact of the growth of talent of various factors. Talent environment in various regions with relative independence, neighboring areas or situations similar comparison will provide a useful reference for the development of various regions, and promoting the region's talent environment towards a more rational and effective direction. (3) The principle of non-repeatability. For any evaluation system, due to the greater impact on the results of duplicate information comprehensive evaluation, easy to increase the weight of individual indicators, so the 
choice of indicators should be fully taken into account in the index of non-repeatability. (4) the principle of universality. Constitute the merits of talent environment is relative, for evaluation in different areas of environmental health personnel evaluation indicators should be universal. (5) the importance of the principle of "Since almost all of the environmental factors will impact on the development of talent, if all factors are included in the evaluation system, both caused by the complexity and difficulty of the operation evaluation system, and difficult to objectively evaluate the impact of each factors play a role. To this end, a number of factors should be screened out of the main factors were evaluated.

The Construction of Personnel Environment Evaluation System. Select Environment Evaluation for talent, often can take social investigation, expert consultation, personnel department personnel approach to statistics. According to these principles as well as the nature of the indicators themselves, we use the Delphi method Talent Index System Environmental Assessment. The system includes five secondary indicators and 18 third-level indicators.

Economic development of a region is a measure of the strength of the region's fundamental symbol, the most fundamental factor in determining the overall social growth of talent. Economic development not only determines the amount of human resources, but also determines the quality of human resources and determines the conditions required for potential mining personnel. Favorable conditions for economic development can promote their talent to best use, so as to continuously meet the material needs of talent in the interests of promoting human body actively to change the nature and society. At the same time, good social and economic environment is conducive to the growth of talent and attracting and retaining talent.

In the economic development in a region directly determine the standard of living and quality of life indicators of per capita GDP. Per capita GDP comparable and dynamic, but also the talent environment decided the most direct and fundamental indicator of economic development. After China joined the W TO comprehensive and international standards, the economic development of a city apparently inseparable from the international market, thus the total import and export per capita and per capita actual use of foreign investment of these two indicators can better reflect the openness and the participation of a city competition in the world market situation. The urban per capita disposable income and the total retail sales of social consumer goods index reflect the level of urban economic life of urban residents.

On an economic basis, an important indicator of the impact the growth of talent status in an area is the development of entrepreneurial talent and security situation in which people in which the soft environment. In addition to personnel concerned with the conditions and quality of life, economic development level of the material, but also concerned about the guarantees of entrepreneurship and development. Macro, government needs through the creation of a series of institutions, policies, and create a fair competitive external environment for the growth of talent; microscopically, should be established within the enterprise to meet the development requirements of the knowledge economy era and the growth of talent incentive mechanism to adapt the social environment, including career development, human resources development of freedom, freedom of the flow of talent, talent and motivation of job satisfaction, interest distribution mechanism, fair and equitable mechanism for social

Safeguard mechanism, goal setting mechanism, the mechanism set expectations, reasonable talent group effects. The situation is both a talent basis macro-control, it but also motivates talented people, and tap potential, enhance awareness of key innovations. Measure to protect health and the development of entrepreneurial talent can be in many ways, such as a region can provide a good platform for business support and development of human resources, the regional government's attention to the situation of talent, with or without the establishment of personnel funds, corporate post-doctoral workstations, study Pioneer Center as well as science and technology investment. We introduced a number of select Pioneer Park students, students studying science and technology enterprises and the creation of the proportion of expenditure allocated three indicators reflect the security situation and the development of entrepreneurial talent.

Talent is the most essential characteristics of creativity and it is mainly embodied by the quality 
of science and technology education and national health. Comrade Jiang Zemin has pointed out that "innovation is the soul of a nation," science and technology education and national quality situation is not only the potential of a region's future development, and also an important stimulus conditions talent innovation and development, not only reflects the culture of quality and the basic quality of society, but also important relying on the talent growing environment. Science and technology education and the status of national quality measure from two aspects: First, the contribution rate of scientific and technological progress. Scientific and technological progress contribution rate reflects a regional science and technology development level and the development of education, represents a region's most advanced social productive forces, the outlook index talent environment. For this reason, we chose to agricultural science and technology contribution to economic growth and the share of industrial science and technology contribution to economic growth indicator reflects the two share contribution of scientific and technological progress. The second is the quantity and quality of talent. Under certain environmental impact talent and promote the fundamental factor in the development and progress of a region is a talent in itself. Therefore, the quantity and quality of personnel largely determines the level of talent in the region. We chose people per million people and the number of colleges and universities in the enrollment ratio of the total population of the two indicators reflect the number of people in the local environment; select undergraduate or higher accounted for more than talent and more talent than the two intermediate grade indices reflect the local environment quality talent.

The city is the main place for the development of modern science and technology and culture, the environment is the main growth of talent. Development of the city's main hard environment determines the growth of talent and life. Urban development includes many aspects of the city's economic, social, and environmental scale. City size is before urban development indicators, means that the material elements of urban space and economic agglomeration in the number of difference and hierarchy, including the urban population, and urban economic activity and the ability to build part of the urban area of three interrelated. Since the economic development has been used as the main indicators of environmental impact of the brain are considered, in order to avoid autocorrelation, the choice of the size of the urban population to represent the size of the city from variables.

In addition, the quality of the urban environment and living standards will determine the quality of life of the people of the region. Today in the pursuit of sustainable development, environmental protection has become an economic-oriented targets into the quality of life of the people of scope of the study. Construction and development of ecological culture make the city a sky blue, to green, camellia, gas net ecological area, the environmental quality of the city by per capita public green area index to reflect.

Social Services and Security in the region is not only a social and cultural foundation, is stable personnel, an important condition for attracting talent, can be reflected through the various social security indicators, such as the coverage of basic medical insurance for urban workers, the rate of unemployment insurance for urban workers, urban Social workers basic pension insurance coverage, the number of beds per million people per million people in the crime rate and the like. Limited availability of data, we selected indicators reflect the number of beds per million people social services and security situation.

\section{The Talent Environment Evaluation of 13 Prefecture-Level Cities In Henan}

By means of multivariate statistical analysis of factor analysis to evaluate talent environment in Henan Province 13 prefecture-level cities. Factor analysis is the study of the correlation matrix of internal dependencies, a plurality of variable consolidated into a few factors to reproduce a statistical analysis of correlation between the index and factors. Solutions include a full factor models and factor structure in two ways. Form factor model is based on the regression equation of the metric X1, Xm factor expressed as a linear combination of Fn F1 factor structure is to reflect the relationship between the index and factors by correlation coefficient. According to personnel statistics summary information and Henan Statistical Yearbook (2011-2015) average of four years 
of data to calculate the original data 18 to obtain the above indicators; then use SPSS12 0 Factor analysis software module, the raw data were normalized, excluded. Effect of different dimensions; then obtained by rotating each variable factor model factor loading matrix, contribution rate and cumulative contribution rate; the conclusion that 13 cities factor score and total score, reflecting the attractiveness of the city personnel situation, thus talent judge the merits of each city environment. The results can be seen, the initial 18 indicators can be grouped into three common factors and the cumulative contribution rate of the three common factors to achieve 81.932 percent, reflecting the original index has concentrated most of the information. And each common factor in only a few indicators of the load factor is large, so you can load these 18 indicators according to the level of the appropriate classification. We found: The first common factor in the index X1, X2, X3, X4, X5, X6, $\mathrm{X} 7, \mathrm{X} 9, \mathrm{X} 10$ has a greater load, mainly from the economic development, and the development of entrepreneurial talent safeguard health, science and technology aspects of health reflect the talent environment, so the first common factor named economic and technological factors; second common factor in the index X8, X11, X12, X13, X14, greater load, mainly reflecting the talent from the National quality Education and health aspects environment, the second factor named public education factor; a third common factor in index X15, X16, X17, greater load on the X18, mainly reflecting the talent environment from urban development and social services and the guarantee of respect Therefore the third factor common factor named for the city. According to the city of Henan Province, 13 prefecture-level talent environment of public factor scores and the respective contribution rate, we can draw comprehensive factor score function, and thus of the 13 cities to be sorted. Integrated talent environment factor score function: $\mathrm{F}=0368 * \mathrm{~F} 1+0297 * \mathrm{~F} 2+0154 *$ F3.

(1) Economic and Technological Factors Sort. Economic science and technology factor scores are sorted, you can find: Henan in the sector in Zhengzhou, Luoyang and Xinxiang in the economic and scientific factors in scores among the best; followed Anyang, Kaifeng, Jiaozuo, Pingdingshan, Nanyang, Xinyang and other cities along the river, and Zhoukou, Zhumadian, Sanmenxia, economic and scientific factors in Puyang four cities scored lower. This basically reflects the pattern of economic development in Henan. After the present, Zhengzhou, Luoyang, Xinxiang area has formed a virtuous economic cycle, in particular the establishment of a large industrial park, the scale of foreign investment increased personnel policy easing, field personnel can freely access and enjoy the preferential treatment. Such talent environment has continued to appeal for the development of talent provides a good external environment.

(2) Education Factor Sort. Sort of education factor scores can be found: Zhengzhou topped the list, followed by Xinxiang, Luoyang, Kaifeng, Jiaozuo, Nanyang, Xinyang, Anyang, Xuchang, Zhumadian, Zhoukou, Luohe. Zhengzhou, because many colleges and universities, rich human resources, senior personnel of education, job title is relatively high, so the score Zhengzhou factor in education is much higher than other cities. As the economic conditions are not developed in the cities of Luoyang and Xinxiang, because of its scientific and technological progress contribution rate for large industrial and agricultural, so education is relatively high ranking factor. Thus, the other prefecture-level city there is considerable potential yet to be excavated at strengthening scientific and technological progress to promote economic and social development, it can continue to explore business-oriented multi-level, multi-form cooperation and research, forming a common key technological achievements with independent intellectual property rights granted important, the economic and social development has a leading role, and accelerate the transformation of the scientific and technological achievements. Meanwhile, in view of Henan has a good advantage and open science, as at the end of 2014, the province's total of 123 colleges and universities, students in 124 million, research and development institutions 3584, rich human resources. Thus, science and technology education backward regions should be introduced preferential policies to attract talent, perform willing to invest, willing to develop, willing

Training Human resource development strategy, guide the rational of human resources, effective configuration.

(3) City Factors Sort. Sort of urban factor scores can be found: the higher Luoyang, Zhengzhou, 
Kaifeng, Jiaozuo, Xinyang, Nanyang city in six urban factor scores, and Zhumadian, Sanmenxia, three cities Zhoukou City in Henan Province ranked scores prefecture-level city in the last three. According to urban planning point of view of ecological theory, the modern city is a kind of artificial fragile ecosystem, which is the depletion of the ecological processes, rather than a chain circulating on the management system. Therefore, urban construction should first promote ecological construction, emphasizing the systematic urban construction, naturalization, the economic and humane. In this regard, the city scores high in Luoyang, for example, in recent years, urban planning special attention to the area of Luoyang urbanization ecological planning and management, the relationship between the ecological relationship suburban, urban natural ecology and human ecology Construction the relationship between ecological construction and ecological environment construction industry, human settlements construction and landscape ecological construction relationship. Thus, by ecological industry incubator, induced ecological environment to nurture and promote ecological culture of an eco-efficient technologies, management system and harmonious system is responsible for social behavior, and promote the coordinated development of economy and the environment. This is also to attract talent and human resources development has laid a good foundation for the hardware. Luoyang, Henan successful experience of other cities in the construction provides a useful reference.

(4) Comprehensive Factor Sort. Overall, cities in North and South Henan and Henan in areas of the city there is a relatively large gap, so all aspects of the Southeast of the city from the talent environment may be improved, in order to break the boundaries between regions of Henan Province, to achieve full overall provincial human resources and rational allocation. In this regard, I think we should achieve a breakthrough in the following aspects: (1) increase in the Southeast region of the fiscal support efforts to adhere to the science and technology investment as a strategic investment, investment in science and technology to ensure the financial stability growth. (2) increase in the Southeast region of industrial policy to support efforts to strengthen mutual coordination science and technology and economic policies continue to promote the implementation of scientific and technological achievements and high-tech industrialization policy. (3) increase in the Southeast region of the support technology start-ups, technology start-ups to relax market access, improve entrepreneurial support service system, smooth universities, research institutions and enterprises between mutually talent flow channels, truly free flow of talent, and create a good environment innovative city construction.

\section{Acknowledgements}

Fund Project: 2015 annual Henan Science and Technology Department, Science and Technology soft science project (152400410395)

\section{References}

[1] Michael Porter. Competitive Advantage. Huaxia Publishing House. 2005

[2] Jiang Zemin's Speech Met Engage in Technology Research and Development Plan. Tenth Anniversary of the Implementation of the Work When Delegates.

[3] Yu Jianying. Computer Engineering, Vol. 30 (2004) No 19, p.144-145

[4] Wang Kuailiang. Mining machinery, Vol. 29 (2008) No 27, p.21-23

[5] Wang Rusong. New Quality Management, Vol. 8 (2006) No 27, p.57-60 